\title{
Publisher's Note: X-ray shadow imprint of hydrodynamic instabilities on the surface of inertial confinement fusion capsules by the fuel fill tube [Phys. Rev. E 95, 031204(R) (2017)]
}

\author{
A. G. MacPhee, D. T. Casey, D. S. Clark, S. Felker, J. E. Field, S. W. Haan, B. A. Hammel, J. Kroll, \\ O. L. Landen, D. A. Martinez, P. Michel, J. Milovich, A. Moore, A. Nikroo, N. Rice, H. F. Robey, \\ V. A. Smalyuk, M. Stadermann, and C. R. Weber \\ (Received 19 June 2017; published 27 June 2017)
}

\section{DOI: 10.1103/PhysRevE.95.069905}

This paper was published online on 30 March 2017 with an error in Fig. 2(c) and in the text on page 4. On page 4, left-hand column, the thirteenth line of the second paragraph should read as "ablated should be $1 / 4 \times 2.0 \mu \mathrm{m} / \mathrm{ns} \times 0.3 \mathrm{~ns} \approx 150 \mathrm{~nm}$. (The...." Figure 2(c) has been replaced and the text has been corrected as of 16 June 2017. The figure and text are incorrect in the printed version of the journal. For the benefit of the print readership, Fig. 2 has been replicated below.
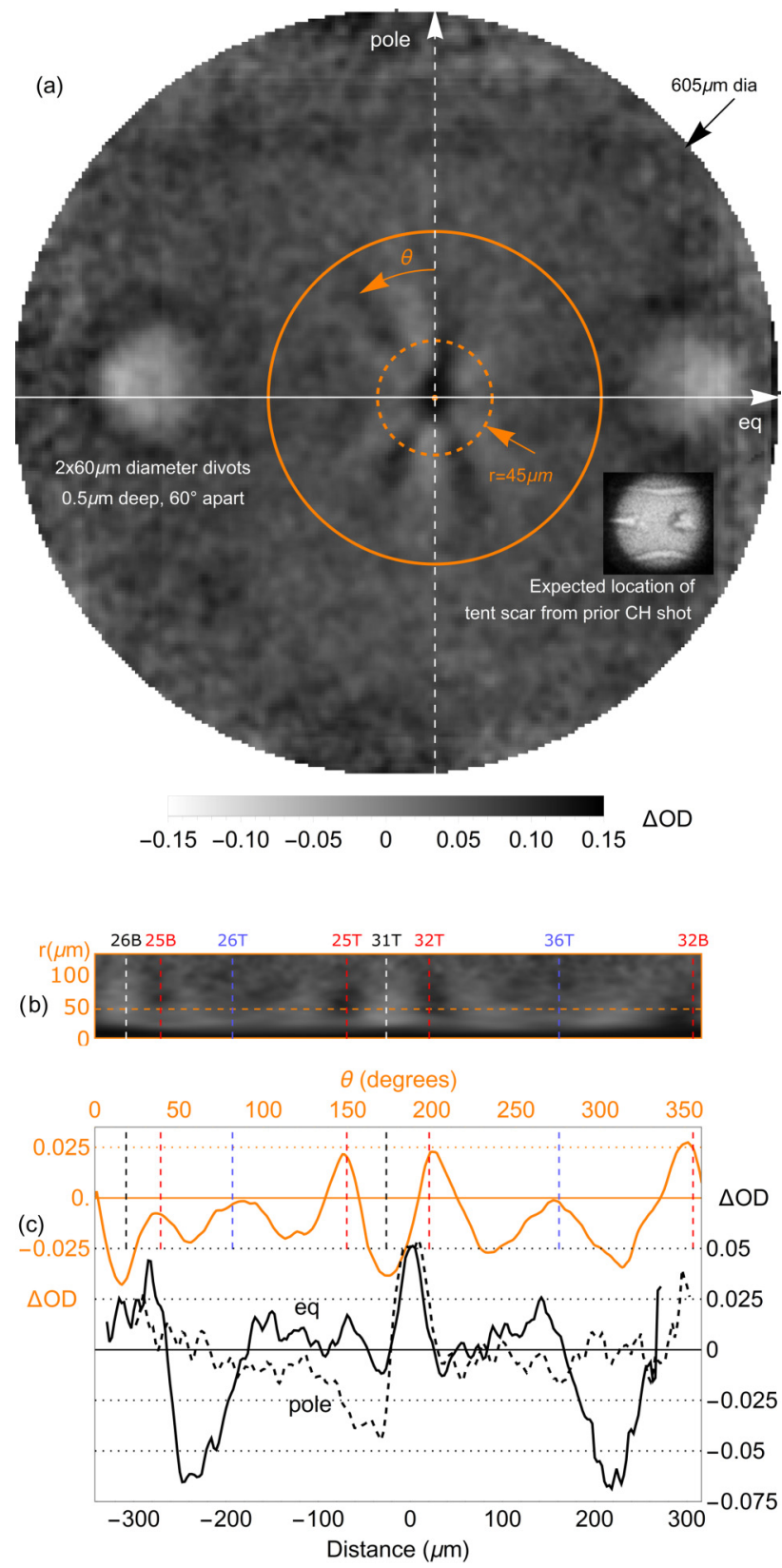

FIG. 2. Optical density modulation in (a) spatial coordinates, (b) $r, \theta$ coordinates, (c) lineouts along the equator, pole, and $\theta$ at $r=45 \mu \mathrm{m}$. Inset: Radiograph for a $\mathrm{CH}$ capsule showing expected tent location. The dashed lines in (b) correspond to the ray-traced orientation of the fill tube shadows. 